\title{
Nitrite Reductase Gene Upregulated During Conidiation Is Involved in Macroconidium Formation in Fusarium oxysporum
}

\author{
Y. Iida, T. Kurata, Y. Harimoto, and T. Tsuge
}

Graduate School of Bioagricultural Sciences, Nagoya University, Chikusa, Nagoya 464-8601, Japan.

Current address of first author: National Institute of Vegetable and Tea Science, 360, Kusawa, Tsu 514-2392, Japan.

Accepted for publication 7 July 2008.

\section{ABSTRACT}

Iida, Y., Kurata, T., Harimoto, Y., and Tsuge, T. 2008. Nitrite reductase gene upregulated during conidiation is involved in macroconidium formation in Fusarium oxysporum. Phytopathology 98:1099-1106.

Fusarium oxysporum produces three kinds of asexual spores, microconidia, macroconidia, and chlamydospores. We previously found that the transcript level of the nitrite reductase gene of $F$. oxysporum, named FoNIIA, was markedly upregulated during conidiation compared with during vegetative growth. FoNIIA was also found to be positively regulated by Ren 1 that is a transcription regulator controlling development of microconidia and macroconidia. In this study, we analyzed the function of FoNIIA in conidiation of $F$. oxysporum. Conidiation cultures showed markedly higher level of accumulation of FoNiiA protein as well as FoNIIA mRNA than vegetative growth cultures. FoNIIA protein was sig- nificantly decreased in cultures of the REN1 disruption mutant compared with that of the wild type. These results confirmed that FoNIIA expression is upregulated during conidiation and is positively regulated by REN1. The FoNIIA disruption mutants produced microconidia, macroconidia, and chlamydospores, which were morphologically indistinguishable from those of the wild type. The mutants, however, produced significantly fewer macroconidia than the wild type, although the wild type and mutant strains produced similar numbers of microconidia and chlamydospores. These results demonstrate that nitrite reductase is involved in quantitative control of macroconidium formation as well as nitrate utilization in F. oxysporum.

Additional keywords: F. oxysporum f. sp. melonis, pathogenicity.
Asexual sporulation (conidiation) is a common reproductive mode for fungi (8). In plant diseases, conidia generally act as disseminated propagules, which can be responsible for initiating infection (10). Although the molecular biology of conidiation has been characterized in detail for two experimental fungi, Aspergillus nidulans and Neurospora crassa $(1,23,41)$, the genetic and molecular mechanisms of conidiation remain largely undefined in plant-pathogenic fungi.

The soilborne fungus Fusarium oxysporum is an economically important plant pathogen with worldwide distribution $(3,4,12)$. This fungus contains about 100 intraspecific variants called formae speciales, which cause vascular wilts on different plants $(3,4,12)$. F . oxysporum produces three kinds of asexual spores, microconidia, macroconidia, and chlamydospores (Fig. 1) (29). Microconidia are ellipsoidal and have no or one septum (Fig. 1A). Macroconidia are falcate and have three or four septa (Fig. 1B). Globose chlamydospores have thick walls (Fig. 1C). These asexual spores play important roles in the disease cycle of $F$. oxysporum. Microconidia and macroconidia are produced on the stem surface of infected plants and serve as secondary inocula to spread the fungus to the neighboring host plants; chlamydospore is a thick-walled spore that enables a fungus to survive unfavorable conditions and acts as the primary inocula $(9,20,35,36)$.

We previously identified two genes, RENI and FoSTUA, which encode different types of transcription regulators essential for conidiation of $F$. oxysporum $(32,33)$. REN1 encodes a protein

Corresponding author: T. Tsuge; E-mail address: ttsuge@agr.nagoya-u.ac.jp

* The $\boldsymbol{e}$-Xtra logo stands for "electronic extra" and indicates that the online version contains a figure showing vegetative growth and pathogenicity of the FoNIIA disruption mutants.

doi:10.1094/PHYTO-98-10-1099

(C) 2008 The American Phytopathological Society with similarity to the A. nidulans MedA, which has been identified as a developmental regulator of conidiation $(6,32)$. Targeted mutation of REN1 resulted in defective development of microconidia and macroconidia, and the mutants form rod-shaped, conidium-like cells directly from hyphae. The mutants, however, exhibited normal chlamydospore formation (32). FoSTUA encodes a basic helix-loop-helix protein with similarity to the $A$. nidulans StuA $(13,33)$. The FoSTUA disruption mutants exhibited normal microconidium formation. The mutants, however, lacked conidiophores, resulting in defective development of macroconidia. In contrast, chlamydospore formation was dramatically promoted in the mutants. Thus, FoSTUA is a positive and negative regulator for the development of macroconidia and chlamydospores, respectively (33).

We performed expressed sequence tag (EST) analysis during conidiation for discovery of additional genes required for conidiation in $F$. oxysporum (17). We constructed cDNA libraries from two cultures, carboxymethyl cellulose-amended liquid medium (CMCLM) cultures producing microconidia and macroconidia and complete liquid medium (CLM) cultures not producing conidia. A total of 626 and 641 unique genes from CMCLM and CLM libraries, respectively, were identified, and only 130 $(\approx 20 \%)$ were common in the two libraries. The transcript levels of 496 genes specific for the conidiation library were studied by real-time quantitative polymerase chain reaction (RT-PCR), revealing 42 genes with an over fivefold increase in expression during conidiation conditions (17).

We also compared the transcript levels of 496 conidiation library-specific genes between the wild type and the REN1 disruption mutant or the FoSTUA disruption mutant (18). A total of 35 and three genes were markedly different (over 10-fold increase or decrease) in the transcript levels between the wild type and the REN1 disruption mutant or the FoSTUA disruption mutant, respectively (18). These analyses found that the nitrite reduc- 
tase gene, named FoNIIA, was upregulated during conidiation and positively regulated by REN1 $(17,18)$.

Utilization of nitrate requires two enzymes, nitrate reductase and nitrite reductase. Nitrate reductase catalyzes the reduction of nitrate to nitrite, and nitrite reductase catalyzes the reduction of nitrite to ammonium (25). We observed that the transcript level of the nitrate reductase gene was not significantly induced in CMCLM cultures and was not regulated by Ren1 $(17,18)$. These results suggested that nitrite reductase has an important function in conidiation as well as nitrate utilization. In this study, we analyzed the function of nitrite reductase in conidiation of $F$. oxysporum. Conidiation cultures of the wild-type strain showed markedly higher level of accumulation of FoNiiA protein as well as FoNIIA mRNA than vegetative growth cultures. Targeted mutation of FONIIA resulted in a significant reduction in macroconidia, but not microconidia and chlamydospores, in conidiation cultures. We propose that nitrite reductase has the function to promote macroconidium formation in $F$. oxysporum.

\section{MATERIALS AND METHODS}

Fungal strains and culture conditions. Strains Mel02010 (JCM9288) and DR1 (REN1 disruption mutant) of F. oxysporum f. sp. melonis $(28,32)$ were used in this study. DR1 was generated from Mel02010 by transformation-mediated disruption of REN1 (32). Strains were maintained routinely on potato dextrose agar (PDA; Difco, Detroit, MI).

To compare the transcript and protein levels of FoNIIA between conidiation and vegetative growth cultures of $F$. oxysporum, strains were grown in CMCLM ( $15 \mathrm{~g}$ of carboxymethyl cellulose, $1 \mathrm{~g}$ of $\left(\mathrm{NH}_{4}\right)_{2} \mathrm{SO}_{4}, 1 \mathrm{~g}$ of $\mathrm{KH}_{2} \mathrm{PO}_{4}, 0.5 \mathrm{~g}$ of $\mathrm{MgSO}_{4} \cdot 7 \mathrm{H}_{2} \mathrm{O}$, and $1 \mathrm{~g}$ of yeast extract per liter) (7) and CLM ( $1 \mathrm{~g}$ of $\mathrm{Ca}\left(\mathrm{NO}_{3}\right)_{2}, 0.2 \mathrm{~g}$ of $\mathrm{KH}_{2} \mathrm{PO}_{4}, 0.25 \mathrm{~g}$ of $\mathrm{MgSO}_{4} \cdot 7 \mathrm{H}_{2} \mathrm{O}, 0.15 \mathrm{~g}$ of $\mathrm{NaCl}, 0.02 \mathrm{~g}$ of $\mathrm{FeCl}_{3}$, $10 \mathrm{~g}$ of glucose, $1 \mathrm{~g}$ of yeast extract, and $1 \mathrm{~g}$ of peptone per liter) (39) at $25^{\circ} \mathrm{C}$ for 5 days on an orbital shaker (100 rpm). To analyze effects of nitrogen sources on the transcript and protein levels of FoNIIA during vegetative growth, strains were grown in $50 \mathrm{ml}$ of minimal liquid medium (MLM; $1 \mathrm{~g}$ of ammonium tartrate, $0.2 \mathrm{~g}$ of $\mathrm{KH}_{2} \mathrm{PO}_{4}, 0.5 \mathrm{~g}$ of $\mathrm{MgSO}_{4} \cdot 7 \mathrm{H}_{2} \mathrm{O}, 0.15 \mathrm{~g}$ of $\mathrm{NaCl}, 0.02 \mathrm{~g}$ of $\mathrm{FeCl}_{3}$, and $10 \mathrm{~g}$ of glucose per liter) (39) at $25^{\circ} \mathrm{C}$ for 3 days, and the resulting mycelia were transferred to $50 \mathrm{ml}$ of MLM supplemented with $0.1 \%$ ammonium tartrate or $0.1 \% \mathrm{NaNO}_{2}$ as a sole nitrogen source in $100-\mathrm{ml}$ Erlenmeyer flasks and grown at $25^{\circ} \mathrm{C}$ for $24 \mathrm{~h}$ on an orbital shaker (100 rpm). These cultures were subjected to isolation of RNA and proteins.

Nucleic acid isolation and manipulation. Isolation of total DNA and RNA from F. oxysporum was performed as previously described $(18,28,37)$. Poly $(\mathrm{A})^{+}$RNA was isolated from total RNA with the Oligo dT30 mRNA Purification Kit (Takara Bio, Shiga, Japan) according to the manufacturer's instructions. Plasmid DNA and bacterial artificial chromosome (BAC) DNA were extracted by the standard methods (38).
Restriction enzyme digestion of fungal genomic DNA and fractionation in agarose gels were performed by the standard methods (38). Fractionated DNA was transferred to Hybond N+ nylon membranes (GE Healthcare Bio-Sciences, Piscataway, NJ) and subjected to hybridization and detection using Gene Images Random-Prime Labeling and Detection Reagents (GE Healthcare Bio-Sciences) according to the manufacturer's instruction. PCR was performed using Taq DNA polymerase (Takara Bio).

DNA sequences were determined with the BigDye Terminator Cycle Sequencing Ready Reaction Kit (Applied Biosystems, Warrington, UK) and an automated fluorescent DNA sequencer (Model 373A, Applied Biosystems) according to the manufacturer's instructions. DNA sequences were analyzed with BLAST program (2).

Real-time quantitative PCR was performed in a LightCycler Quick System 350S (Roche Diagnostic, Indianapolis, IN) using the One Step SYBR RT-PCR Kit (Takara Bio) as previously described $(17,18)$. The PCR primers 2 F02-f $\left(5^{\prime}\right.$-GTC AGA AGC GAC CAG CTT TC-3') and 2F02-r (5'-GAT ACC GTT TGG CAA CTC GT-3') were designed to amplify an FoNIIA cDNA fragment of 120-bp using the primer design software in DNAsis Pro Ver. 2.2 (Hitachi Software Engineering, Yokohama, Japan). Previously designed and optimized primers FOMefF (5'-ACT TAC CCC GCC ACT TGA G-3') and FOMefR (5'-CCA GGC GTA CTT GAA GGA AC-3') for the elongation factor 1- $\alpha$ gene $(E F 1 \alpha)$ as a constitutively expressed endogenous control $(17,18)$ were used. The transcript level of FoNIIA was measured four times with independently isolated RNA. To verify that the efficiencies of the target (FoNIIA) and endogenous control reactions were approximately equal, reactions were performed with serial dilutions of RNA as templates. The threshold cycle was calculated with a LightCycler Software version 3.5 (Roche Diagnostic) using the second-derivative-maximum method (LightCycler Operator's Manual version 3.5, Roche Diagnostic), and the transcript levels in samples were calculated from the genespecific standard curve $(17,18)$. The transcript level of FoNIIA was normalized to that of $E F 1 \alpha$ (value $=1)$.

Genomic library. A genomic BAC library of Mel02010 was constructed with a BAC vector pcc1BAC (Epicentre, Madison, WI). Chromosome-sized DNA molecules in agarose plugs were partially digested with Sau3AI (Takara Bio) and fractionated in a $1.0 \%$ certified low melt agarose (Bio-Rad Laboratories, Richmond, CA) gel on a contour-clamped homogeneous electric field (CHEF) apparatus (CHEF-DRII; Bio-Rad Laboratories) as previously described (16). A piece of agarose containing DNA fragments of about $150 \mathrm{~kb}$ was excised and treated with $\beta$-agarase (New England BioLabs, Ipswich, MA) according to the manufacturer's instructions. Recovered DNA was ligated with BamHIdigested, dephosphorylated pcc1BAC using T4 DNA ligase (Takara $\mathrm{Bio})$. Ligation products were transformed by electroporation into Escherichia coli ElectroMAX DH10B (Invitrogen, San Diego, CA) using an electroporation apparatus GenePulser (Bio-Rad Labora-
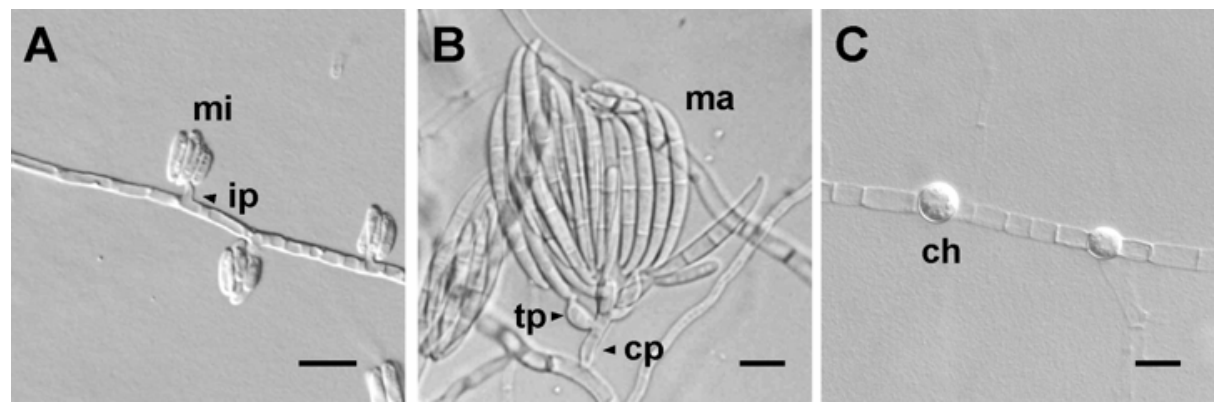

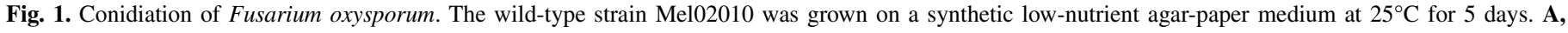

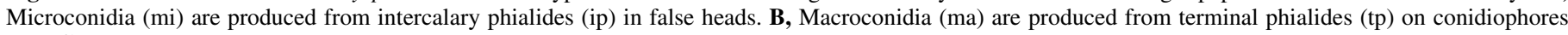
(cp). C, Chlamydospores (ch) are formed from hyphae. Bar markers represent $10 \mu \mathrm{m}$. 
tories), and a total of 3,072 colonies were obtained. The average insert size of 12 clones analyzed was $114.3 \mathrm{~kb}$, and 3,072 clones were expected to contain a total of $351 \mathrm{Mb}$, that is, about 5.9-fold of the F. oxysporum genome size (about $59.9 \mathrm{Mb}$ ).

Colony blotting to Hybond $\mathrm{N}+$ nylon membranes was performed by the standard method (38), and Gene Images RandomPrime Labeling and Detection Reagents were used for colony hybridization.

Isolation of nitrite reductase gene. The insert of EST clone WCMC-2_F02 encoding putative nitrite reductase (17) was used as a probe for screening a genomic BAC library of Mel02010, and a positive clone BACFoNIIA was isolated. An $8.0-\mathrm{kb}$ region containing WCMC-2_F02 sequence was sequenced, and a putative open reading frame (ORF) of FoNIIA was identified.

The FoNIIA cDNA was isolated by reverse transcription-PCR (RT-PCR) using the RNA PCR Kit version 2.1 (Takara Bio). The cDNA was amplified from total RNA $(1 \mu \mathrm{g})$ of Mel02010 with primers NIRf (5'-ATG ACT GCA ACG ACA CAA A-3') and NIRr (5'-CTA CCA TTC CGG CGC AC-3') (Fig. 2A) according to the manufacturer's instructions. NIRf and NIRr contain the FoNIIA initiation and termination codons (italics), respectively. RT-PCR products were cloned into the plasmid pCR2.1 (Invitrogen) to determine the sequences.

The sequence of FoNIIA has been deposited in DDBJ/ EMBL/GenBank databases under accession no. AB274526.

Preparation of protein extracts and immunoblotting. Fungal tissues $(500 \mathrm{mg})$ were suspended in $300 \mu \mathrm{l}$ of protein extraction buffer (10 mM Tris-HCl, pH 7.5, $1 \mathrm{mM}$ dithiothreitol, $2 \%$ sodium dodecyl sulfate (SDS), $5 \mathrm{mM}$ EDTA, and complete protease inhibitor cocktail set (Roche) 1 tablet per $50 \mathrm{ml}$ ) and broken by agitation with zirconia beads $(3.0 \mathrm{~mm})$ at $4^{\circ} \mathrm{C}$ for $3 \mathrm{~min}$ using Micro Smash MS-100R (TOMY, Tokyo, Japan). After centrifugation at $1,600 \times g$ for $10 \mathrm{~min}$, the supernatants of the lysates were collected. All protein concentration was determined by the Bradford method (5) using Bio-Rad Protein Assay Kit (Bio-Rad) with bovine serum albumin as a standard.

Total protein samples were separated by SDS-polyacrylamide gel electrophoresis using NuPAGE 4 to $12 \%$ Bis-Tris Gel (Invitrogen) and blotted to Hybond-ECL (GE Healthcare BioSciences) by using an electroblotting apparatus Trans-Blot Semi-Dry (Bio-Rad Laboratories). FoNiiA protein was detected using the antibody raised against an epitopic peptide (CTRNMELEDDRGQKR) of FoNiiA conjugated to keyhole limpet hemocyanin in rabbit (prepared by Takara Bio). Antibody binding was visualized using enhanced chemiluminescence (ECL) western blotting detection system (GE Healthcare Bio-Sciences) after binding a horseradish peroxidase-conjugated secondary antibody.

Fungal transformation. The FoNIIA disruption vector pGDN1 was constructed by cloning the $1.6-\mathrm{kb}$ internal fragment of FoNIIA into the integrative transformation vector pSH75 (21), which carries hygromycin B resistance gene $(h p h)$. The 1.6-kb FoNIIA fragment was amplified by PCR with primers DNf $\left(5^{\prime}-\right.$ TCG TGG GGT TGG GCA TGG TT-3') and DNr (5'-CCT GCT TCT TGG CAC CAA AC-3') (Fig. 2A). The amplified DNA was cloned into the EcoRV site of pSH75 to make pGDN1.

The complementation vector pCON1 was constructed by cloning the entire FoNIIA with the In-Fusion Dry-Down PCR Cloning Kit (Clontech, Mountain View, CA). The 7.4-kb fragment, which includes the FoNIIA exon and intron region and its 2.0-kb upstream and 2.0-kb downstream regions, was amplified from BACFoNIIA DNA by PCR using primers CNf (5'-CGA AGT TAT CAG TCG ACG CAT GTG CCT TAT GTA GAG-3') and CNr (5'-AAT GGT CTA GAA AGC TCT ACC ATT CCG GCG CAC CGC-3') (Fig. 2A). These primers have 16 bases (underlined) identical to sequences at the ends of the linearized plasmid pDNR-CMV (Clontech). The In-Fusion cloning reaction and transformation in E. coli Fusion-Blue Competent Cells
(Clontech) yielded the FoNIIA complementation vector pCON1. The plasmid pCON1 was introduced into the FoNIIA disruption mutant by co-transformation with the transformation vector pII99 (27), which carries geneticin resistance gene (nptII).

Protoplast preparation and transformation of $F$. oxysporum were performed as previously described (19). Transformants carrying $h p h$ or $n p t I I$ were selected on regeneration medium containing hygromycin B (Wako Pure Chemicals, Osaka, Japan) at $100 \mu \mathrm{g} / \mathrm{ml}$ or geneticin (Gibco BRL, Life Technology, Gaithersburg, MD) at $150 \mu \mathrm{g} / \mathrm{ml}$, respectively $(19,27)$. To assess nitrite utilization of transformants, transformants were grown on minimal agar medium (MAM; MLM supplemented with 2\% agar) (39) containing $0.1 \%$ ammonia tartrate or $0.1 \% \mathrm{NaNO}_{2}$ as a sole nitrogen source.

Test for conidiation. To induce conidiation of $F$. oxysporum strains, two media were used: CMCLM for formation of microconidia and macroconidia and synthetic low nutrient agar medium (SNA; $1.0 \mathrm{~g}$ of $\mathrm{KH}_{2} \mathrm{PO}_{4}, 0.5 \mathrm{~g}$ of $\left(\mathrm{NH}_{4}\right)_{2} \mathrm{SO}_{4}, 0.5 \mathrm{~g}$ of $\mathrm{MgSO}_{4} \cdot 7 \mathrm{H}_{2} \mathrm{O}, 0.5 \mathrm{~g}$ of KCI, $0.2 \mathrm{~g}$ of glucose, $0.2 \mathrm{~g}$ of sucrose, and $20 \mathrm{~g}$ of agar per liter) (31) for formation of microconidia, macroconidia, and chlamydospores. Sterilized filter paper $(1 \times$ $2 \mathrm{~cm}$ ) was placed on SNA surface before inoculation of fungal strains (31).

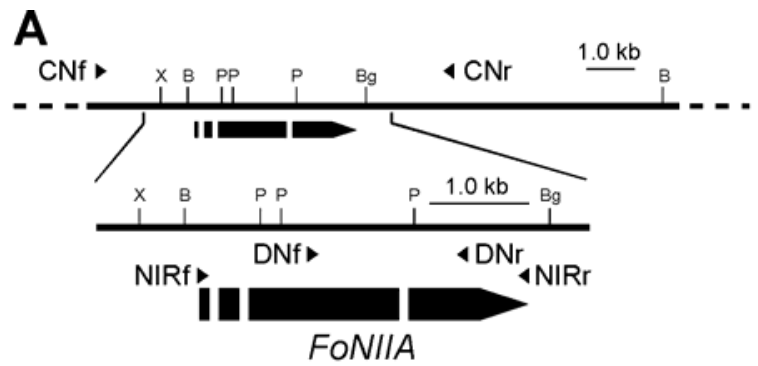

B

\begin{tabular}{|c|c|}
\hline & \\
\hline is & \\
\hline NCHINTKR & \\
\hline LPRML KGWDANGVFVYRTIEDLNKLI KFSNDKKGT & 160 \\
\hline GGGLLGLEAAKAMLDLETFNRVDVIERAQWVLTRQID & 200 \\
\hline GKMVADQVSQLGVNLNLGKGVS SMKTDENNNLTGVIF & 240 \\
\hline SEI SC STLCFAVGVKPRDDLARSANLEVGQRGG I VVNDDL & 280 \\
\hline RTSMPDIYAIGECASWRGMAYGLIAPGVAMAEVVA & 3 \\
\hline AKLH SPQTFKTPDMSTKLKLLGVNVAS FGDCFADRDGPVT & \\
\hline LPPKYARTLVNGDAKE PKAVQALTYKDPFSNVYKKYIFTK & 4 \\
\hline DGKYLLGGMMI GDVCDYVKLLPMVKAQKELEI SPSELILG & 440 \\
\hline AKKDGGEDTDDLDDD AQVCSCHNVTKGDIVKVVKDGTCKD & 480 \\
\hline VAS IKKCTKAGTGCGGCVPLI TTI FNKTMA & 520 \\
\hline CSHFNH SRADLFNI IMVKRLKNMGEVMREAGNDKEALGCE & 560 \\
\hline LCKPVVAS IMASLWNRHVMDKTTHGLQETNDRFLGNIQRD & 600 \\
\hline GTYSVVPRVSGGEITPDKLVVIGEVAQKYNLYTKITGGQR & 640 \\
\hline IDLFGAQKQDLLDIWGQLVAGGMESGHA YAKSLRTVKSCV & 6 \\
\hline GS TWCRFGLSD SVGMAVRLEERYKS IRAPHKI KGGVSGCV & 720 \\
\hline RECAEAQGKDFGLIATEKGWNI FVGGNGGANPRHAELLAK & 7 \\
\hline LMFYMRTADKLQRTARWIENLPGGI & 800 \\
\hline YLOEVILEDKLGINA SLEAQMEELVDSFFDEWAEAIKS & 840 \\
\hline IAAKFKQFANTNDTTRNMELEDDRGQKRPAFWPADAAA & 880 \\
\hline NFSGLKDKWSMTSWEP I IESSY FDGADELPNGI SATVF & 920 \\
\hline DTQLAIWRI KGVYYATQQMCPHKRAF I LSDGLIGQEF & 960 \\
\hline & 1000 \\
\hline PTEA & \\
\hline & \\
\hline & \\
\hline
\end{tabular}

Fig. 2. The nitrite reductase gene FoNIIA of Fusarium oxysporum. A, Map of the FoNIIA locus. The arrowed bar indicates FoNIIA with introns (white segments). Arrowheads denote the location of oligonucleotide primers used in polymerase chain reaction (PCR) and reverse transcription-PCR experiments. B, BamHI; Bg, BglII; P, PvuII; X, XbaI. B, Amino acid sequence of FoNiiA. I to IV, NADH/FAD-binding domain, ferredoxin-like binding domain, nitrite and sulphite reductase domain, and Rieske domain, respectively. 
The wild type and mutant strains were grown on PDA at $25^{\circ} \mathrm{C}$ for 5 days. Agar blocks (3-mm diameter) carrying mycelia were prepared from the resulting colonies and inoculated in $50 \mathrm{ml}$ of CMCLM in a 100-ml Erlenmeyer flask. Each strain was inoculated in two sets of five flasks, and each set was incubated at $25^{\circ} \mathrm{C}$ for 5 days on an orbital shaker $(100 \mathrm{rpm})$ under continuous fluorescent light or dark condition (7). For each flask, the numbers of microconidia and macroconidia were counted twice using a microscope.

A PDA block carrying mycelium was inoculated on SNA-paper medium, $5 \mathrm{~mm}$ away from filter paper pieces. Each strain was inoculated on two sets of five SNA-paper plates, and each set was incubated at $25^{\circ} \mathrm{C}$ for 5 days under continuous fluorescent light or dark condition. For each plate, numbers of chlamydospores formed in 5-mm squares between agar blocks and filter paper were counted using a microscope.

Test for vegetative growth and pathogenicity. To test for vegetative growth of $F$. oxysporum strains, they were grown on three agar media: PDA, complete agar medium (CAM; CLM supplemented with 2\% agar) (39), and MAM. CAM and MAM were supplemented with $0.1 \%$ ammonium tartrate as a sole nitrogen source. PDA blocks (3 $\mathrm{mm}$ in diameter) carrying mycelia were inoculated on PDA, CAM, and MAM. After incubation at $25^{\circ} \mathrm{C}$ for 5 days, colony growth and morphology were recorded.

Pathogenicity was tested by a root-dip inoculation of susceptible melon (Cucumis melo L.) cultivar Amus with bud cell suspensions $\left(\approx 1 \times 10^{6}\right.$ cells $/ \mathrm{ml}$ in sterilized water $)$ as previously described (28). Fifteen seedlings with a single true leaf were inoculated with bud cell suspension of each strain. Pathogenicity was also tested by planting 15 seedlings with a single true leaf in soil infested with bud cells $\left(\approx 1 \times 10^{5}\right.$ cells/g of soil) of each strain. Disease symptoms were observed 3 weeks after inoculation.

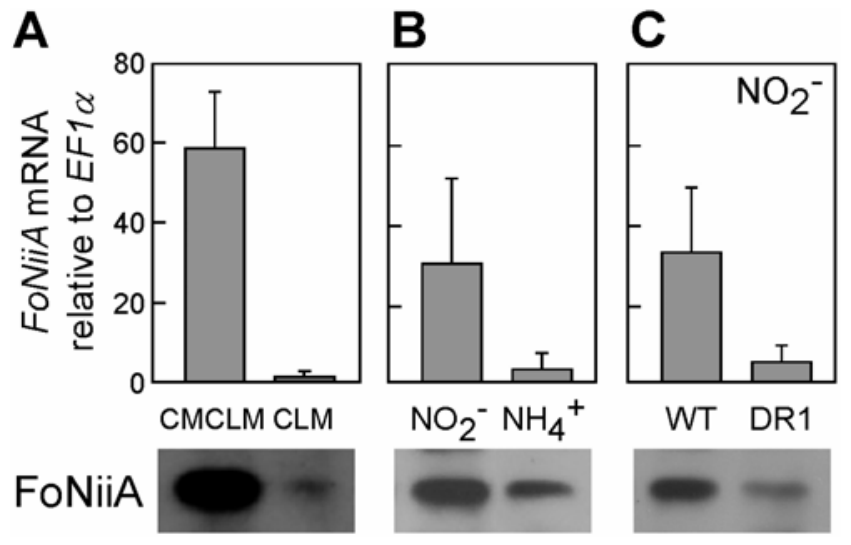

Fig. 3. Transcript (upper column) and protein (lower column) levels of FoNIIA. Transcript level of FoNIIA in each culture was quantified by quantitative real-time polymerase chain reaction (PCR) analysis and normalized to that of $E F 1 \alpha($ value $=1)$. Each value represents the mean and standard deviations of four experiments with independently isolated RNA. FoNiiA protein was detected by immunoblot analysis with anti-FoNiiA antibody. Total proteins $(10 \mu \mathrm{g})$ from each culture were separated by sodium dodecyl sulfatepolyacrylamide gel electrophoresis and blotted on nitrocellulose membranes. The blots were treated with anti-FoNiiA antibody, and antibody binding was visualized using enhanced chemiluminescence (ECL) western blotting detection system after binding a horseradish peroxidase-conjugated secondary antibody. A, The wild-type strain Mel02010 was grown in carboxymethyl cellulose-amended liquid medium (CMCLM; conidiation phase) and complete liquid medium (CLM; vegetative growth phase) at $25^{\circ} \mathrm{C}$ for 5 days. B, Mel02010 was grown in minimal liquid medium (MLM) supplemented with $\mathrm{NaNO}_{2}\left(\mathrm{NO}_{2}^{-}\right)$or ammonium tartrate $\left(\mathrm{NH}_{4}{ }^{+}\right)$as a sole nitrogen source. $\mathbf{C}$, Me102010 (WT) and the REN1 disruption mutant (DR1) were grown in MLM supplemented with $\mathrm{NaNO}_{2}\left(\mathrm{NO}_{2}^{-}\right)$.

\section{RESULTS AND DISCUSSION}

Isolation of FoNIIA. A BAC clone, named BACFoNIIA, was isolated by screening of a BAC genomic library of Mel02010 using the insert of EST clone WCMC-2_F02 carrying the partial cDNA of putative nitrite reductase gene as a probe. Sequencing of the $8.0-\mathrm{kb}$ region of BACFoNIIA detected a putative ORF encoding a protein with strong similarity to nitrite reductases from fungi (Fig. 2A).

The cDNA of $3.3 \mathrm{~kb}$ was prepared from total RNA of Mel02010 by RT-PCR with primers NIRf and NIRr (Fig. 2A). Comparison of the genomic sequence with that of RT-PCR product indicated that the gene has three introns (53, 50, and 51 bp) and four exons $(65,151,1,973$, and 1,079 bp) and potentially encodes a 1,089-amino acid protein.

A database search using BLAST algorithm revealed that the deduced amino acid sequence has strong similarity to those of fungal nitrite reductases, such as A. nidulans NiiA (34) and $N$. crassa Nit-6 (14) with 62.3 and $61.6 \%$ identity, respectively. The cloned gene encodes four domains typical of nitrite reductases: NADH/FAD-binding domain, ferredoxin-like binding domain, conserved domain in nitrite and sulphite reductases, and Rieske domain containing iron-sulfur clusters (Fig. 2B) (14,40). Thus, this gene was named FoNIIA.

Expression of FoNIIA. F. oxysporum produces microconidia and macroconidia in CMCLM, but not in CLM, and exhibits vigorous vegetative growth in CLM $(17,32,33)$. The transcript and protein levels of FoNIIA in the wild-type strain Mel02010 were tested in CMCLM (conidiation) cultures and CLM (vegetative growth) cultures by real-time quantitative PCR and immunoblot analyses, respectively. FoNIIA showed 63-fold higher transcript level in CMCLM cultures than in CLM cultures (Fig. 3A). FoNiiA protein was markedly abundant in CMCLM cultures compared to CLM cultures (Fig. 3A). These results indicate that the transcript level of FoNIIA is upregulated during conidiation, resulting in increase of FoNiiA protein.

Nitrite reductase catalyzes the reduction of nitrite to ammonium (25). We also tested the transcript and protein levels of FoNIIA in Mel02010 grown in MLM containing $\mathrm{NaNO}_{2}$ or ammonium tartrate as a sole nitrogen source. The transcript level of FoNIIA was 12-fold higher in $\mathrm{NaNO}_{2}$ cultures than in ammonium tartrate cultures, and FoNiiA protein was more abundant in $\mathrm{NaNO}_{2}$ cultures than in ammonium tartrate cultures (Fig. 3B), indicating that FoNIIA expression is induced in nitrite medium.

We previously found that FoNIIA is positively regulated by the transcription regulator Ren1, essential for conidiation of $F$. oxysporum (32). The wild-type strain Mel02010 and the REN1 disruption mutant DR1 were grown on MAM containing ammonium tartrate or $\mathrm{NaNO}_{2}$ as a sole nitrogen source at $25^{\circ} \mathrm{C}$ for 6 days, and colony diameters were measured. The wild type and mutant strains showed similar growth on ammonium tartrate medium (Fig. 4A). The REN1 disruption mutant, however, showed poor growth on $\mathrm{NaNO}_{2}$ medium compared with the wild type (Fig. 4A). Although the wild type and mutant strains did not differ in growth on $\mathrm{NaNO}_{2}$ medium during the initial 2 days of incubation, colony growth of the mutant was restricted after that (Fig. $4 \mathrm{~A}$ and B). Such poor growth of the REN1 disruption mutant on $\mathrm{NaNO}_{2}$ medium was probably due to the lower expression level of FoNIIA. The expression level of FoNIIA was compared between the wild type and the mutant grown in MLM supplemented with $\mathrm{NaNO}_{2}$. The transcript level of FoNIIA was 11-fold lower in the mutant than in the wild type, and accumulation of FoNiiA protein was less in the mutant than in the wild type (Fig. 3C). These results confirmed that FoNIIA is positively regulated by Ren 1 .

In addition of nitrite reductase, nitrate reductase is also required for nitrate utilization: this enzyme catalyzes the reduction of nitrate to nitrite, the first step for nitrate assimilation (25). However, we previously observed that the nitrate reductase gene 
was not significantly induced in CMCLM cultures and was not regulated by Ren1 $(17,18)$. Deng et al. (11) found using cDNA array with 3,372 tentative unique transcripts that the nitrite reductase gene was highly expressed in conidia and germinated conidia, but not in vegetative mycelia, of $F$. oxysporum. All these data suggested that nitrite reductase has an important function in conidiogenesis and conidial germination as well as nitrate utilization.

Targeted disruption of FoNIIA. To examine the function of FoNIIA in nitrite utilization and conidiation in $F$. oxysporum, homologous recombination was employed to disrupt FoNIIA with the plasmid pGDN1, which contains a 1.6-kb internal fragment of FoNIIA and the $h p h$ cassette (Fig. 5A). Strain Mel02010 was transformed with pGDN1, and 19 transformants were isolated. When these transformants were grown on MAM containing ammonium tartrate or $\mathrm{NaNO}_{2}, 12$ transformants exhibited normal growth on both media. The remaining seven transformants (DN1 to DN7) exhibited normal growth on ammonium medium, but exhibited very poor growth on nitrite medium (Fig. 5B), suggesting that these transformants were deficient in nitrite utilization due to disruption of FoNIIA.
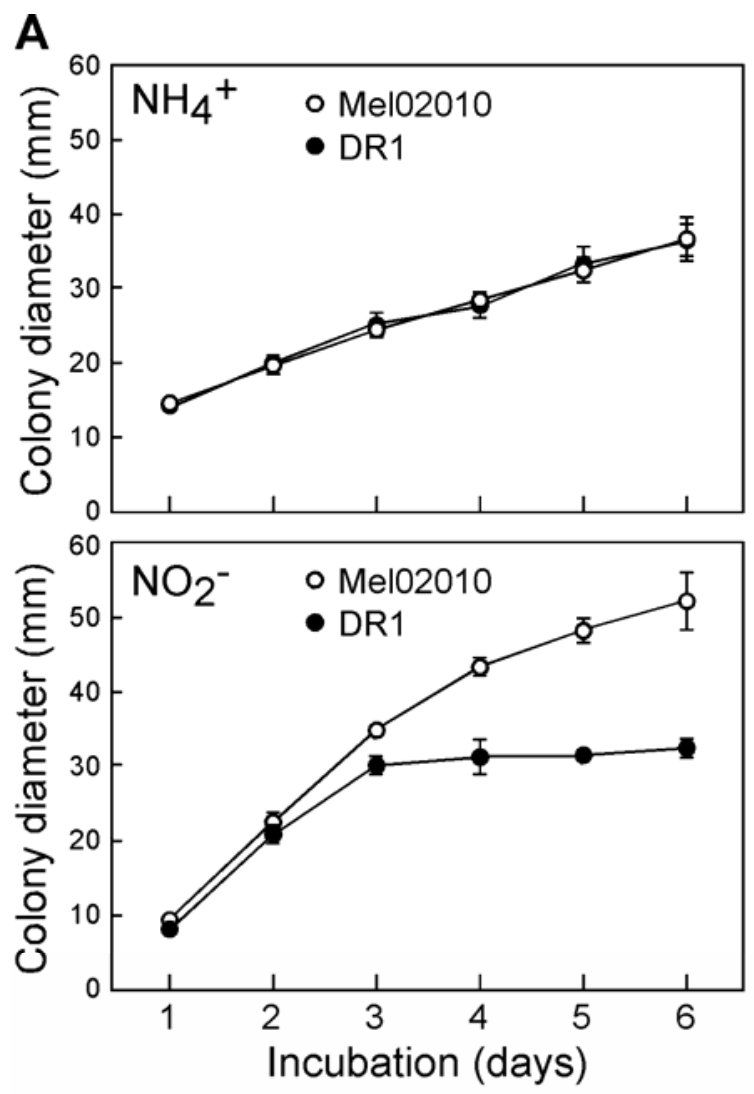

B

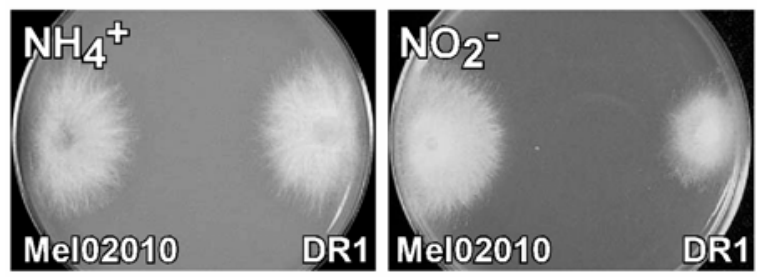

Fig. 4. Colony growth of the REN1 disruption mutant on ammonium and nitrite media. The wild-type strain Mel02010 and the REN1 disruption mutant DR1 were grown on minimal agar medium supplemented with ammonium tartrate $\left(\mathrm{NH}_{4}^{+}\right)$or $\mathrm{NaNO}_{2}\left(\mathrm{NO}_{2}^{-}\right)$as a sole nitrogen source at $25^{\circ} \mathrm{C}$, and colony diameters were measured at 24 -h intervals. A, Data represent the means and standard deviations of three replications. B, Photographs were taken after 4 days of incubation.
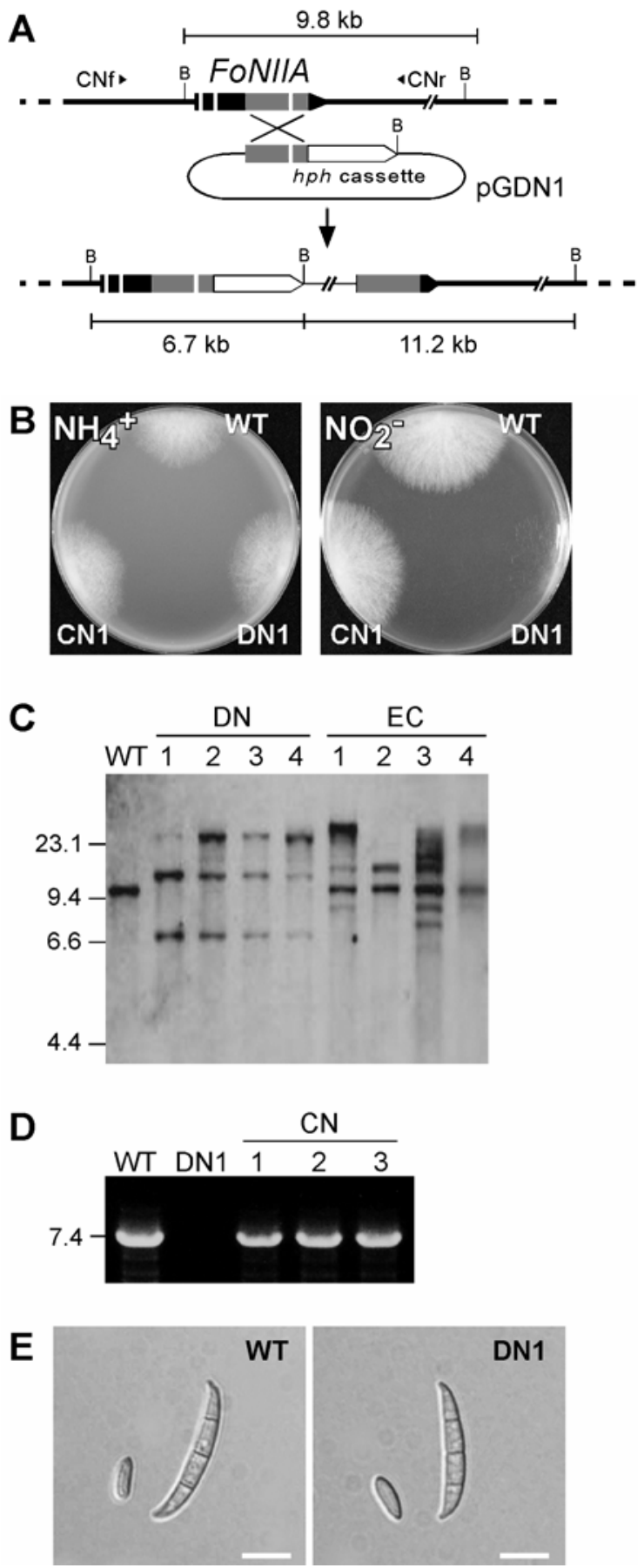

Fig. 5. Transformation-mediated disruption of FoNIIA. A, Structure of the FoNIIA locus before and after homologous integration of the FoNIIA disruption vector pGDN1. To make pGDN1, the 1.6-kb internal fragment of FoNIIA was cloned into the transformation vector $\mathrm{pSH75}$. B, BamHI. B, Growth of the FoNIIA disruption mutant on ammonium and nitrite media. Strains were grown on minimal agar medium supplemented with ammonium tartrate $\left(\mathrm{NH}_{4}^{+}\right)$or $\mathrm{NaNO}_{2}\left(\mathrm{NO}_{2}^{-}\right)$as a sole nitrogen source at $25^{\circ} \mathrm{C}$ for 4 days. WT, wild-type strain Mel02010; DN1, FoNIIA disruption mutant; CN1, FoNIIAcomplemented transformant made from DN1. C, DNA gel blot analysis of pGDN1 transformants. Total DNA $(0.5 \mu \mathrm{g} / \mathrm{lane})$ from Mel02010 and the pGDN1 transformants was digested with BamHI and fractionated in a $0.8 \%$ agarose gel. The blot was probed with the 1.6-kb FoNIIA fragment from pGDN1. Sizes (in kilobases) of marker DNA fragments (HindIII-digested $\lambda$ DNA) are indicated on the left. DN1 to DN4, FoNIIA disruption mutants; EC1 to EC4, ectopic transformants. D, Polymerase chain reaction (PCR) analysis of genetic complementation of FoNIIA disruption mutant. Total DNA from each strain was used as templates for PCR with primer pair CNf and CNr. CN1 to CN3, FoNIIA-complemented transformants made from DN1. E, Microconidia and macroconidia produced by Mel02010 and DN1. Strains were grown in carboxymethyl cellulose-amended liquid medium at $25^{\circ} \mathrm{C}$ for 4 days under continuous fluorescent light. Bar markers represent $10 \mu \mathrm{m}$. 
The integration mode of pGDN1 in four transformants (DN1 to DN4) showing poor growth on nitrite medium was analyzed by DNA gel blot analysis. As controls, four transformants (EC1 to EC4) showing normal growth on nitrite medium were also used. Total DNA of Mel02010 and transformants was digested with $B a m H I$, and the blot was probed with the 1.6-kb FoNIIA fragment cloned in pGDN1 (Fig. 5A). The probe hybridized to $\approx 9.8-\mathrm{kb}$ bands in the wild-type strain and EC transformants (Fig. 5A and C). We expected that the probe would hybridize to $\approx 6.7$ - and $\approx 11.2$-kb bands, instead of $\approx 9.8$-kb band, in DN transformants, if FoNIIA was disrupted by homologous integration of pGDN1 into the FoNIIA locus (Fig. 5A). The hybridization patterns of DN transformants were consistent with expected ones (Fig. 5C).

To confirm disruption of FoNIIA in DN transformants, genetic complementation of the FoNIIA disruption mutant DN1 with the wild-type FoNIIA was performed. The plasmid pCON1, which contains the entire FoNIIA exon and intron regions with the upstream and downstream regulatory sequences, was introduced into DN1 by co-transformation with the plasmid pII99, conferring resistance to geneticin (27). When geneticin-resistant transformants were tested for growth on MAM containing ammonium tartrate or $\mathrm{NaNO}_{2}$, three transformants (CN1 to CN3) normally grew on $\mathrm{NaNO}_{2}$ medium as well as ammonium tartrate medium (Fig. 5B). PCR analysis of these transformants with primers $\mathrm{CNf}$ and $\mathrm{CNr}$ verified the presence of the introduced 7.4-kb fragment containing FoNIIA (Fig. 5A and D). These results confirmed that FoNIIA encodes nitrite reductase.

Conidiation of FoNIIA disruption mutants. To assess the role of FoNIIA in conidiation of $F$. oxysporum, formation of microconidia, macroconidia, and chlamydospores of the FoNIIA disruption mutants (DN1 to DN3) was compared with that of the wild-type strain Mel02010, the ectopic pGDN1 transformant EC1, and the FoNIIA-complemented transformant CN1. Strains were grown in CMCLM containing $\left(\mathrm{NH}_{4}\right)_{2} \mathrm{SO}_{4}$ as a sole nitrogen source under continuous fluorescent light or dark condition, and formation of microconidia and macroconidia was observed. The FoNIIA disruption mutants produced microconidia and macroconidia with similar morphology to those produced by the wild type (Fig. 5E), indicating that FoNIIA is not essential for morphogenesis of these conidia.

The expression of FoNIIA is positively regulated by Ren1 (18). REN1 controls the early step of development of microconidia and macroconidia, and the REN1 disruption mutants lack conidiophores and phialides and form rod-shaped, conidium-like cells, instead of microconidia and macroconidia, directly from hypha (32). Thus, we supposed that mutation of FoNIIA might cause morphological abnormality of these conidia. The FoNIIA disruption mutants, however, produced microconidia and macroconidia with normal morphology. These results suggest that Ren1 controls a number of genes including FoNIIA, which function in different steps of the conidiation process, and that FoNIIA may not contribute at the early step of conidiogenesis.

Number of microconidia and macroconidia produced by each stain was counted after incubation in CMCLM for 5 days. Number of microconidia produced by the FoNIIA disruption mutants and the other strains was not significantly different (Fig. 6A). However, number of macroconidia produced by the FoNIIA disruption mutants was significantly fewer than those produced by
A
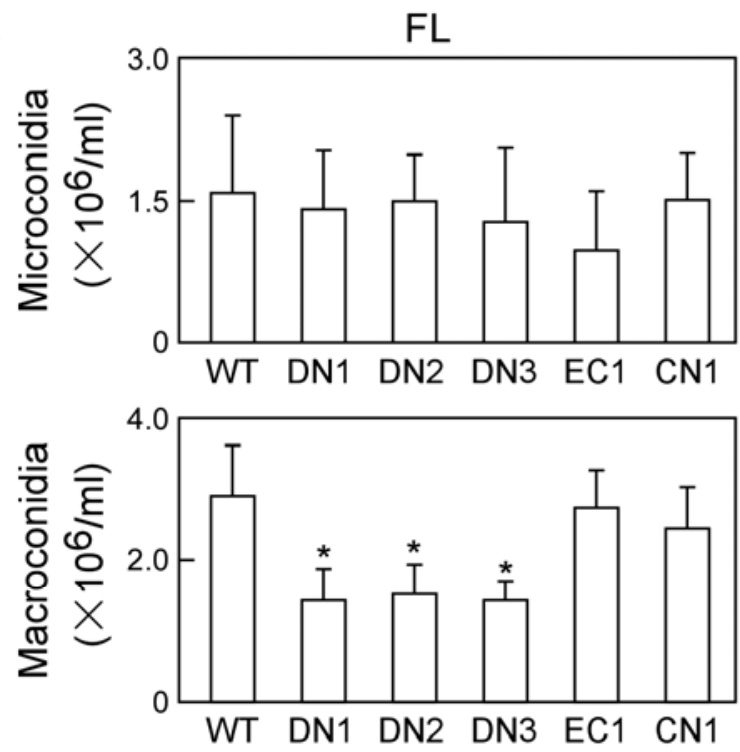

B

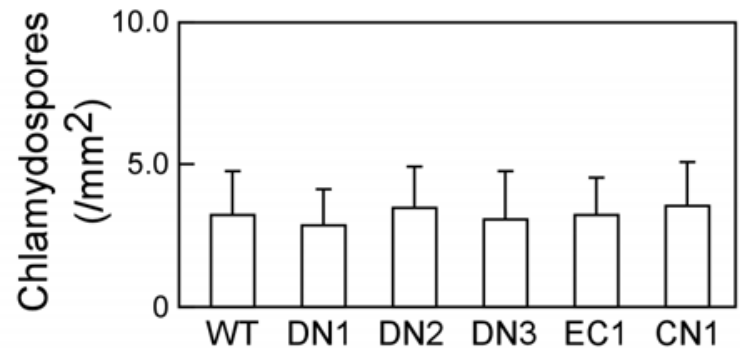

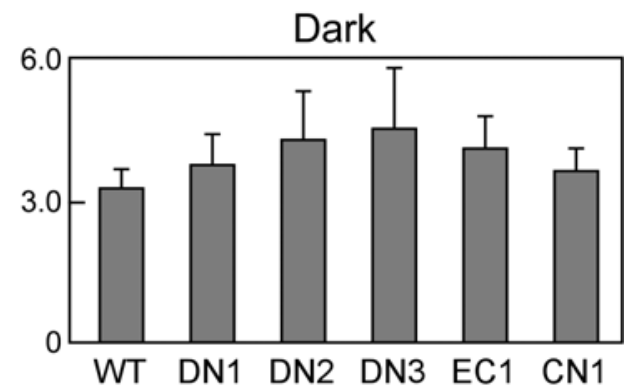
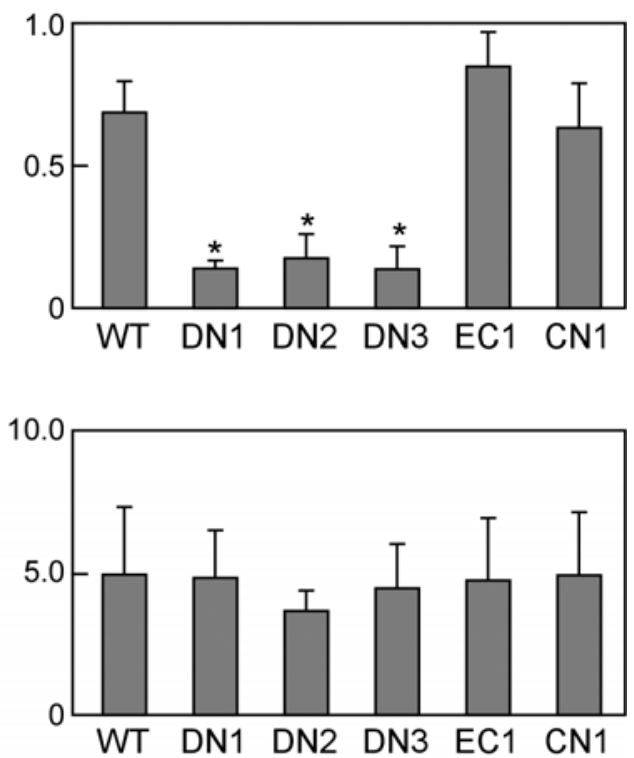

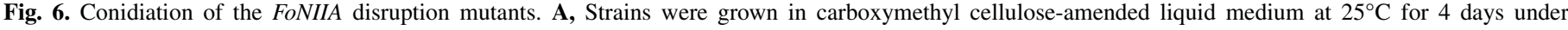

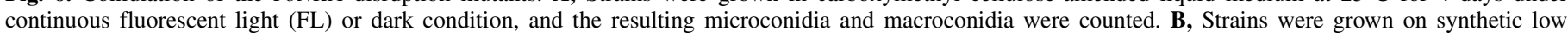

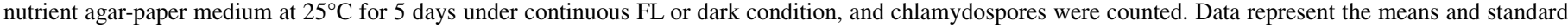

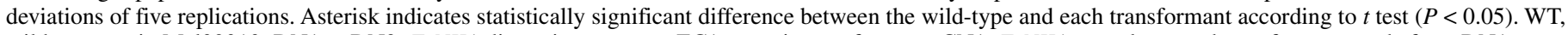
wild-type strain Mel02010; DN1 to DN3, FoNIIA disruption mutants; EC1, ectopic transformant; CN1, FoNIIA-complemented transformant made from DN1. 
the other strains: $\approx 50$ and $20 \%$ of the wild-type strain Mel02010 under continuous fluorescent light and dark conditions, respectively (Fig. 6A). The FoNIIA-complemented transformants produced macroconidia as did the wild type (Fig. 6A).

To observe chlamydospore formation, strains were grown on SNA-paper medium under continuous fluorescent light or dark conditions. The FoNIIA disruption mutants formed chlamydospores acrogenously from hyphae or by the modification of hyphal cells, as did the wild type. The number and morphology of chlamydospores were not significantly different between wild type and mutants under both light and dark conditions (Fig. 6B). Although it was difficult to accurately count numbers of microconidia and macroconidia formed on SNA-paper medium, the mutants produced apparently fewer macroconidia than the wild type under both light and dark conditions. The wild type and mutant strains seemed to produce similar number of microconidia. These results indicate that nitrite reductase is required for wild-type macroconidium formation but not for microconidium and chlamydospore formation.

There were no significant differences in colony growth on PDA, CAM, and MAM between the wild type and the FoNIIA disruption mutants. The FoNIIA disruption mutants caused typical wilt symptoms on melon seedlings, when seedlings were inoculated with bud cell suspension by a root-dip method and were planted in soil infested with bud cells. Timing of symptom appearance and severity of symptoms were indistinguishable on plants inoculated with the wild type and the FoNIIA disruption mutants, indicating that the mutants preserve the ability to infect host plant tissue and to cause disease symptoms under the conditions tested.

The mutation of FoNIIA affected macroconidium formation, but not formation of microconidia and chlamydospores, vegetative growth on ammonium medium, and virulence in $F$. oxysporum. The genetic role of nitrite reductase in quantitative control of macroconidum formation is uncertain. The effect of mutation of nitrite reductase genes on conidiation has not been reported in any fungi, including $A$. nidulans and $N$. crassa. Because we used CMCLM containing $\left(\mathrm{NH}_{4}\right)_{2} \mathrm{SO}_{4}$ as a sole nitrogen source in test for formation of microconidia and macroconidia, nitrite reductase activity was not required for nutritional nitrogen supply in both the wild type and the FoNIIA disruption mutants. Thus, different function of nitrite reductase is likely to have a role in macroconidium formation. Nitrite reductase is also involved in denitrification process, in which this enzyme generates nitric oxide (NO) from nitrite (44). Nitric oxide is known as a potent signaling molecule with multiple biological functions in animal and plants $(26,43)$. In fungi, nitric oxide was reported to be involved in sporangiophore development of Phycomyces blakesleeanus (24), photo-conidiation of $N$. crassa (30), conidiation of Coniothyrium minitans (15), and conidial germination of Aspergillus fumigatus (22) and Colletotrichum coccodes (42). Nitric oxide production in these fungi was identified to be mediated by nitric oxide synthases (NOS), but not nitrite reductases $(15,24,30,42)$. Therefore, further studies to detect nitric oxide generation during conidiation in the wild type and the FoNIIA disruption mutant should be performed.

We previously found 35 genes, which were markedly different ( $>10$-fold increase or decrease) in the transcript levels between the wild type and the REN1 disruption mutant (18). Of 35 genes, 26 including FoNIIA correspond to upregulated genes in CMCLM cultures of the wild-type strain, which were identified by the EST analysis of CMCLM and CLM cultures (17). Of the 26 genes, 16 are of unknown function. The remaining 10 genes possibly encode proteins with significant similarity to known proteins, such as membrane transporters, transcription factors, V-SNARE involved in vacuolar transport, small monomeric GTPase, and iron transferase $(17,18)$. These genes provide candidates for further studies directed at understanding fungal conidiogenesis and its molecular regulation. Gene-disruption studies are in progress to determine whether any of these genes are required for conidial development of $F$. oxysporum. This approach will provide a unique and novel insight into conidiogenesis of $F$. oxysporum that provides the infectious propagules playing important roles in the disease cycle of this pathogen.

\section{ACKNOWLEDGMENTS}

We thank T. Ohara for valuable suggestions and the Radioisotope Research Center, Nagoya University, for technical assistance. This work was supported by grants-in-aids from Japan Society for the Promotion of Science (T. Tsuge) and a Research Fellowship from Japan Society for the Promotion of Science for Young Scientists (Y. Iida).

\section{LITERATURE CITED}

1. Adams, T. H., Wieser, J. K., and Yu, J. H. 1998. Asexual sporulation in Aspergillus nidulans. Microbiol. Mol. Biol. R. 62:35-54.

2. Altschul, S. F., Madden, T. L., Schäfer, A. A., Zhang, J., Zhang, Z., Miller, W., and Lipman, D. J. 1997. Gapped BLAST and PSI-BLAST: A new generation of protein database search programs. Nucleic Acids Res. 25:3389-3402

3. Armstrong, G. M., and Armstrong, J. K. 1981. Formae speciales and races of Fusarium oxysporum causing wilt diseases. Pages 391-399 in: Fusarium Disease, Biology and Taxonomy. P. E. Nelson, T. A. Toussoum, and R. J. Cook, eds. The Pennsylvania State University Press, University Park, PA.

4. Beckman, C. H. 1987. The Nature of Wilt Diseases of Plants. The American Phytopathological Society Press, St. Paul, MN.

5. Bradford, M. M. 1976. A rapid and sensitive method for the quantitation of microgram quantities of protein utilizing the principle of protein-dye binding. Anal. Biochem. 72:248-254.

6. Busty, T. M., Miller, K. Y., and Miller, B. L. 1996. Suppression and enhancement of the Aspergillus nidulans medusa mutation by altered dosage of the bristle and stunted genes. Genetics 143:155-163.

7. Cappellini, R. A., and Peterson, J. L. 1965. Macroconidium formation in submerged cultures by a nonsporulating strain of Gibberella zeae. Mycologia 57:962-966.

8. Cole, G. T. 1986. Models of cell differentiation in conidial fungi. Microbiol. Rev. 50:95-132.

9. Couteaudier, Y., and Alabouvette, C. 1990. Survival and inoculum potential of conidia and chlamydospores of Fusarium oxysporum f. sp. lini in soil. Can. J. Microbiol. 36:551-556.

10. Dahlberg, K. R., and Van Etten, J. L. 1982. Physiology and biochemistry of fungal sporulation. Annu. Rev. Phytopathol. 20:218-301.

11. Deng, Y., Dong, H., Jin, Q., Dai, C., Fang, Y., Liang, S., Wang, K., Shao, J., Lou, Y., Shi, W., Vakalounakis, D. J., and Li, D. 2006. Analysis of expressed sequence tag data and gene expression profiles involved in conidial germination of Fusarium oxysporum. Appl. Environ. Microbiol. 72:1667-1671

12. Di Pietro, A., Madrid, M. P., Caracuel, Z., Delgado-Jarana, J., and Roncero, M. I. G. 2003. Fusarium oxysporum: Exploring the molecular arsenal of a vascular wilt fungus. Mol. Plant Pathol. 4:315-325.

13. Dutton, J. R., Johns, S., and Miller, B. L. 1997. StuAp is a sequencespecific transcription factor that regulates developmental complexity in Aspergillus nidulans. EMBO J. 16:5710-5721.

14. Exley, G. E., Colandene, J. D., and Garrett, R. H. 1993. Molecular cloning, characterization, and nucleotide sequence of nit- 6 , the structural gene for nitrite reductase in Neurospora crassa. J. Bacteriol. 175:23792392.

15. Gong, X., Fu, Y., Jiang, D., Li, G., Yi, X., and Peng, Y. 2007. L-arginine is essential for conidiation in the filamentous fungus Coniothyrium minitans. Fungal Genet. Biol. 44:1368-1379.

16. Hatta, R., Shinjo, A., Ruswandi, S., Kitani, K., Yamamoto, M., Akimitsu, K., and Tsuge, T. 2006. DNA transposon fossils present on the conditionally dispensable chromosome controlling AF-toxin biosynthesis and pathogenicity of Alternaria alternata. J. Gen. Plant Pathol. 72:210219.

17. Iida, Y., Ohara, T., and Tsuge, T. 2006. Identification of genes upregulated during conidiation of Fusarium oxysporum through expressed sequence tag analysis. Fungal Genet. Biol. 43:179-189.

18. Iida, Y., Ohara, T., and Tsuge, T. 2007. Identification of genes with changes in transcriptuion levels cause by mutations in conidiation regulator genes REN1 and FoSTUA in Fusarium oxysporum. J. Gen. Plant Pathol. 73:158-167. 
19. Inoue, I., Ohara, T., Namiki, F., and Tsuge, T. 2001. Isolation of pathogenicity mutants of Fusarium oxysporum f. sp. melonis by insertional mutagenesis. J. Gen. Plant Pathol. 67:191-199.

20. Katan, T., Shlevin, E., and Katan, J. 1997. Sporulation of Fusarium oxysporum f. sp. lycopersici on stem surface of tomato plants and aerial dissemination of inoculum. Phytopathology 87:712-719.

21. Kimura, N., and Tsuge, T. 1993. Gene cluster involved in melanin biosynthesis of the filamentous fungus Alternaria alternata. J. Bacteriol. 175:4427-4435.

22. Kunert, J. 1995. Effect of nitric oxide donors on survival of conidia, germination and growth of Aspergillus fumigatus in vitro. Folia Microbiol. 40:238-244.

23. Lengeler, K. B., Davidson, R. C., D'souza, C., Harashima, T., Shen, W. C., Wang, P., Pan, X., Waugh, M., and Heitman, J. 2000. Signal transduction cascades regulating fungal development and virulence. Microbiol. Mol. Biol. R. 64:746-785.

24. Maier, J., Hecker, R., Rocke, P., and Ninnemann, H. 2001. Role of nitric oxide synthase in the light-induced development of sporangiophores in Phycomyces blakesleeanus. Plant Physiol. 126:1323-1330.

25. Marzluf, G. A. 1997. Genetic regulation of nitrogen metabolism in the fungi. Microbiol. Mol. Biol. R. 61:17-32.

26. Mur, L. A. J., Carver, T. L. W., and Prats, E. 2006. NO way to live; the various roles of nitric oxide in plant-pathogen interactions. J. Exp. Bot. 57:489-505.

27. Namiki, F., Matsunaga, M., Okuda, M., Inoue, I., Nishi, K., Fujita, Y., and Tsuge, T. 2001. Mutation of an arginine biosynthesis gene causes reduced pathogenicity in Fusarium oxysporum f. sp. melonis. Mol. Plant-Microbe Interact. 14:580-584.

28. Namiki, F., Shiomi, T., Kayamura, T., and Tsuge, T. 1994. Characterization of the formae speciales of Fusarium oxysporum causing wilts of cucurbits by DNA fingerprinting with the nuclear repetitive DNA sequences. Appl. Environ. Microbiol. 60:2684-2691.

29. Nelson, P. E. 1981. Life cycle and epidemiology of Fusarium oxysporum. Pages 51-80 in: Fusarium Wilt Diseases of Plants. M. E. Mace, A. A. Bell, and C. H. Beckman, eds. Academic Press, New York.

30. Ninnemann, H., and Maier, J. 1996. Indications for the occurrence of nitric oxide synthases in fungi and plants and the involvement in photoconidiation of Neurospora crassa. Photochem. Photobiol. 64:393398.

31. Nirenberg, H. I. 1990. Recent advances in the taxonomy of Fusarium. Stud. Mycol. 32:91-101.
32. Ohara, T., Inoue, I., Namiki, F., Kunoh, H., and Tsuge, T. 2004. REN1 is required for development of microconidia and macroconidia, but not of chlamydospores, in the plant pathogenic fungus Fusarium oxysporum. Genetics 166:113-124.

33. Ohara, T., and Tsuge, T. 2004. FoSTUA, encoding a basic helix-loophelix protein, differentially regulates development of three kinds of asexual spores, macroconidia, microconidia, and chlamydospore, in the fungal plant pathogen Fusarium oxysporum. Eukaryot. Cell 3:14121422.

34. Pain, A., Woodward, J., Quail, M. A., Anderson, M. J., Clark, R., Collins, M., Fosker, N., Fraser, A., Harris, D., Larke, N., Murphy, L., Humphray, S., O’Neil, S., Pertea, M., Price, C., Rabbinowitsch, E., Rajandream, M. A., Salzberg, S., Saunders, D., Seeger, K., Sharp, S., Warren, T., Denning, D. W., Barrell, B., and Hall, N. 2004. Insight into the genome of Aspergillus fumigatus: Analysis of a $922 \mathrm{~kb}$ region encompassing the nitrate assimilation gene cluster. Fungal Genet. Biol. 41:443-453.

35. Rekah, Y., Shtienberg, D., and Katan, J. 2000. Disease development following infection of tomato and basil foliage by airborne conidia of the soilborne pathogens Fusarium oxysporum f. sp. radicis-lycopersici and $F$. oxysporum f. sp. basilici. Phytopathology 90:1322-1329.

36. Rowe, R. C., Farely, J. D., and Coplin, D. C. 1977. Airborne spore dispersal and recolonization of steamed soil by Fusarium oxysporum in greenhouses. Phytopathology 67:1513-1517.

37. Saitoh, K., Togashi, K., Arie, T., and Teraoka, T. 2006. A simple method for a mini-preparation of fungal DNA. J. Gen. Plant Pathol. 72:348-350.

38. Sambrook, J., and Russell, D. W. 2001. Molecular Cloning: A Laboratory Manual. 3rd ed. Cold Springer Laboratory, Cold Springer Harbor, NY.

39. Sanderson, K. E., and Srb, A. M. 1965. Heterokaryosis and parasexuality in the fungus Ascochyta imperfecta. Am. J. Bot. 42:72-81.

40. Schneider, D., and Schmidt, C. L. 2005. Multiple Rieske proteins in prokaryotes: Where and why? Biochim. Biophys. Acta 1710:1-12.

41. Springer, M. L. 1993. Genetic control of fungal differentiation: The three pathways of Neurospora crassa. Bioessays 15:365-374.

42. Wang, J., and Higgins, V. J. 2005. Nitric oxide has a regulatory effect in the germination of conidia of Colletotrichum coccodes. Fungal Genet. Biol. 42:284-292.

43. Wendehenne, D., Pugin, A., Klessing, D. F., and Durner, J. 2001. Nitric oxide: Comparative synthesis and signaling in animal and plant cells. Trends Plant Sci. 6:177-183.

44. Zumft, W. G. 1997. Cell biology and molecular basis of denitrification. Microbiol. Mol. Biol. R. 61:533-616. 